\title{
Sulphur and biothiol metabolism determines toxicity responses and fate of mercury in Arabidopsis
}

\author{
Juan Sobrino-Plata ${ }^{1}$, Angel Baron ${ }^{1}$, Cristina Ortega-Villasante ${ }^{1}$, Victor Ortega-Campayo ${ }^{2}$, \\ Cesar González-Berrocal ${ }^{1}$, Carlos Conesa ${ }^{1}$, Sandra Carrasco-Gil ${ }^{3}$, María Muñoz-Pinilla ${ }^{3}$, \\ Javier Abadia ${ }^{3}$, Ana Alvarez-Fernandez ${ }^{3}$, and Luis E. Hernandez ${ }^{1}$ \\ ${ }^{1}$ Universidad Autonoma de Madrid \\ ${ }^{2}$ Universidad Autonoma de Madrid-Cantoblanco Campus \\ ${ }^{3}$ Aula Dei Research Experimental Station-CSIC
}

June 2, 2020

\begin{abstract}
Mercury $(\mathrm{Hg})$ is one of the most hazardous pollutants released by humans and is of global environmental concern. Mercury causes oxidative stress and strong cellular damages in plants, which can be attenuated by the biosynthesis of thiol-rich peptides (biothiols), which include glutathione (GSH) and phytochelatins (PCs). We analysed $\mathrm{Hg}$ tolerance and speciation in five Arabidopsis thaliana genotypes, the wild-type Col-0, three knockdown $\gamma$-glutamylcysteine synthetase $(\gamma E C S)$ mutants and a knockout PC synthase (PCS) mutant. Mercury-PC complexes were detected in roots by HPLC-ESI-TOFMS, with its abundance being limited in $\gamma$ ECS mutants. Analysis of Hg-biothiol complexes in the xylem sap revealed that $\mathrm{HgPC}_{2}$ occurs in wild-type Col-0 Arabidopsis, suggesting that $\mathrm{Hg}$ could be translocated associated with thiol-rich metabolites. Twenty genes involved in sulphur assimilation, GSH and PCs synthesis were differentially expressed in roots and shoots, implying a complex regulation, possibly involving post-translational mechanisms independent of GSH cellular levels. In summary, the present study describes the importance of biothiol metabolism and adequate GSH levels in $\mathrm{Hg}$ tolerance, and identifies for the first time Hg-PC complexes in the xylem sap. This finding supports that Hg-biothiol complexes could contribute to $\mathrm{Hg}$ mobilisation within plants.
\end{abstract}

\section{Introduction}

The often indiscriminate use of mercury $(\mathrm{Hg})$ in several human activities, mostly related with chemical industries and gold-mining, and the use of ineffective waste removal practices has caused a progressive contamination of soils and groundwater worldwide (Selin, 2010). Contamination by this hazardous metal needs to be tackled by using costly cleaning approaches that result in numerous environmental side effects (Chaney et al., 1997), whereas plant innate ability to take up metals can be exploited for soil phytoremediation (Krämer, 2005), in a sustainable low cost manner particularly appealing in Hg polluted areas (He et al., 2015). However, this requires tolerant plants able to withstand cellular damages caused by toxic metal(loid)s (Rascio \& Navari-Izzo, 2011). Among other mechanisms, Hg and other toxic metal(loid)s activate the rapid synthesis of thiol-rich peptides (biothiols) such as glutathione (GSH; $\gamma$ Glu-Cys-Gly) and phytochelatins (PC; ( $\gamma$ Glu-Cys) ${ }_{\mathrm{n}}$-Gly, $n$ ranging from 2 to 11) (Cobbett, 2000). Biothiols play a critical role in toxic metal tolerance by maintaining the intracellular redox balance and binding toxic metals to form less harmful chemical species (Hernández et al., 2015), which are translocated to vacuoles limiting the cytosolic concentration of free metal (Sharma, Dietz, \& Mimura, 2016). Sulphur assimilation and biothiol metabolism are thought to contribute to $\mathrm{Hg}$ tolerance and homeostasis (Carrasco-Gil et al., 2011), but there is still limited knowledge on regulatory mechanisms and how those metabolites mitigate Hg-induced stress.

The overall sulphur acquisition and assimilation pathway is highly conserved in the course of evolution, 
and starts with sulphate up-take by plant roots, but due to its large reduction energetic costs, it is mostly assimilated in leaves after xylematic transportation viadifferent classes of sulphate transporters (SULT) (Gigolashvili \& Kopriva, 2014). Arabidopsis has up to 14 sulphate transporter genes distributed in five groups (AtSULTR1-5 ), with Groups 1 and 2 being more related with S-assimilation (Kopriva, 2006). Once sulphate accumulates at the cytosol, assimilation starts with the synthesis of adenosine phosphosulphate (APS) by adenosine triphosphate sulphurylase (ATPS) from ATP (see pathway shown in Figs. 6 and 7). APS is reduced subsequently by APS reductase (APR), and then sulphite is reduced by sulphite reductase (SiR). The generated sulfhydryl ion binds to O-acetylserine in a step catalysed by OAS-thiol lyase (OAS-TL), synthesizing cysteine (Cys). This thiol-containing amino acid is then used by the enzyme $\gamma$-glutamylcysteine synthetase $(\gamma \mathrm{ECS})$, which ligates Cys to glutamate $(\mathrm{Glu})$, to generate $\gamma$-glutamylcysteine $(\gamma \mathrm{EC})$. Subsequently, glutathione synthetase (GSH-S) forms GSH from Gly and $\gamma \mathrm{EC}$ (Kopriva, Malagoli, \& Takahashi, 2019).

In the present study we evaluate the response of differentArabidopsis thaliana genotypes with altered GSH levels under $\mathrm{Hg}$ stress, using three $\gamma \mathrm{ECS}$ mutant alleles cad2-1, pad2-1 andrax1-1, which contain limited amounts of GSH relative to the wild type (Col-0) (Parisy et al., 2007), and a cad1-3 PCS mutant unable to produce PCs (Cobbett, 2000). It is already known that Hg leads to specific stress alterations in biothiol metabolism in comparison with other toxic metals (Sobrino-Plata et al., 2009), but little information is available about its influence on sulphur metabolism. Hence, we analysed the changes in the transcriptional regulation of sulphate uptake and sulphur assimilation pathway under $\mathrm{Hg}$ stress. In addition, we determined Cys, Glu-Cys, GSH, and PCs accumulation in roots and shoots to assess plant biothiol distribution. Mercury is taken up by roots where is strongly retained (Carrasco-Gil et al., 2011, 2013), and only a small portion is thought to be translocated to shoots via xylem, as occurs with other metal(loid)s (Khodamoradi, Khoshgoftarmanesh, \& Maibody, 2017); but it may be loaded to the xylem as chelated ions (Álvarez-Fernández, Díaz-Benito, Abadía, López-Millán, \& Abadía, 2014). Here, we analysed xylem sap samples from different Arabidopsisgenotypes for detection of $\mathrm{Hg}$-biothiol complexes, and we show the presence of $\mathrm{HgPC}_{2}$ complexes in Arabidopsis wild type, suggesting that $\mathrm{Hg}$ could be transported from the roots to the shoots not only as free ions but also as a biothiol chelated form.

\section{Materials and methods}

\section{Plant material, growth conditions and treatments}

A. thaliana genotypes used were the wild type Columbia 0 (Col-0), the cad2-1, pad2-1 and rax1-1 $\gamma$ ECS mutants and thecad1-3 PCS mutant. Seeds were surface-sterilized by agitation in a $15 \%(\mathrm{v} / \mathrm{v}) \mathrm{NaClO}$ solution for $10 \mathrm{~min}$, followed by several rinses in distilled sterile water. Seeds were germinated on $0.6 \%$

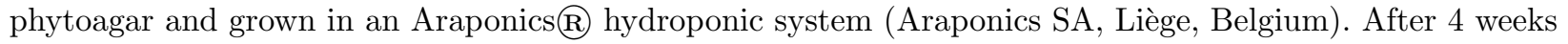
of growth in a short-day light regime $(8 \mathrm{~h}$ light $/ 16 \mathrm{~h}$ darkness $)$ at $25{ }^{\circ} \mathrm{C}$ with a modified Hoagland nutrient solution (Tocquin et al., 2003), the nutrient solution was supplemented with 0 or $3 \mu \mathrm{M} \mathrm{HgCl}_{2}$ and plants were grown for $72 \mathrm{~h}$ more. At harvest, shoots and roots were collected separately and stored at $-80{ }^{\circ} \mathrm{C}$ until analysis.

\section{Chlorophyll fluorescence measurements}

Chlorophyll (Chl) fluorescence was measured at different light regimes to determine $\mathrm{F}_{\mathrm{o}}, \mathrm{F}_{\mathrm{m}}, \mathrm{F}_{\mathrm{m}}, \mathrm{F}_{\mathrm{t}}, \mathrm{F}_{\mathrm{o}}$, $\Phi_{\mathrm{PSII}}, \mathrm{q}_{\mathrm{P}}$ and NPQ, according to (Maxwell \& Johnson, 2000), using a FMS-2 Pulse Modulated Fluorimeter (Hansatech Instruments, Norfolk, UK). Plants were sequentially illuminated with $8000 \mu \mathrm{mol} \mathrm{m}{ }^{-2} \mathrm{~s}^{1}$ saturating pulses and $400 \mu \mathrm{mol} \mathrm{m}{ }^{-2} \mathrm{~s}^{1}$ actinic light.

\section{Mercury tissue concentration}

Organs (approximately $100 \mathrm{mg}$ fresh weight -FW-) were dried at $50{ }^{\circ} \mathrm{C}$ for $72 \mathrm{~h}$, and then digested in $1 \mathrm{~mL}$ of digestion mixture $\left(\mathrm{HNO}_{3}: \mathrm{H}_{2} \mathrm{O}_{2}: \mathrm{H}_{2} \mathrm{O}, 0.6: 0.4: 1 \mathrm{v}: \mathrm{v}\right)$, using an autoclave (Presoclave-75 Selecta, Barcelona, Spain) at $120^{\circ} \mathrm{C}$ and 1.5 atm for 30 min (Ortega-Villasante, Hernández, Rellán-Alvarez, Del Campo, \& Carpena-Ruiz, 2007). Digests were filtered, diluted in Type I water to $6 \mathrm{~mL}$, and $\mathrm{Hg}$ concentrations were 
determined by ICP-MS NexION 300 Perkin-Elmer Sciex (San Jose, CA, USA).

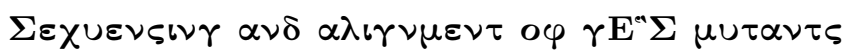

Genomic DNA was isolated from the shoots of Col-0, cad2-1 ,pad2-1 and rax1-1 plants using the illustra DNA Extraction Kit PHYTOPURE (GE Healthcare Life Sciences), and DNA concentration was measured in a NanoDrop? ND-1000 spectrophotometer (Thecnologies Inc., Wilmington, DE, USA). A 637 bp fragment of gene GSH1 ( $\gamma$-glutamylcysteine synthetase, $\gamma$-ECS) was amplified by PCR using primers $\gamma$ ECS01F (CGTTCGGATTATTTCTTGGTGT) and $\gamma$ ECS02R (GCGGTCCTTGTCAGTGTCTGT), and sequenced in an ABI Prism@ 3730/3730xl DNA Sequencer (Certified Scientific Instruments, Inc., USA). Sequences were revised and aligned using the Geneious Pro 5.5.3 software in comparison with GSH1 gene sequence (AT4G23100), and the identity of each mutant was verified as described in literature (Supplementary Fig. 1).

\section{RNA extraction and quantification}

Total RNA from shoots and roots of Arabidopsis was isolated with TRI Reagent (Ambion), cleaned using incolumn DNAse treatment with the RNeasy Mini Kit (Qiagen) (Montero-Palmero, Martín-Barranco, Escobar, \& Hernández, 2013), and quantified n a NanoDrop? ND-1000 spectrophotometer (Thecnologies Inc.). RNA integrity was determined with an Agilent 2100 Bioanalyzer equipped with an RNA 6000 Nano LabChip Kit (Agilent Technologies, Santa Clara, CA, USA) using the RNA integrity number (RIN) algorithm of three independent biological replicates (Schroeder et al., 2006), which showed satisfactory RNA quality in all samples, particularly in those prepared from Hg-treated plants (Supplementary Fig. 2).

\section{Quantitative reverse transcription polymerase chain reaction (qRT-PCR)}

Quantitative reverse transcription (RT)-PCR was performed with RNA fromArabidopsis shoots and roots in two completely independent biological experiments (three RNA biological replicates each) to synthesize the complementary DNA strand.. The RT reaction was performed with random hexamers, using the RETROscript(r) First Strand Synthesis Kit (Applied Biosystems-Life technologies, Carlsbad, CA, USA). Quantitative PCR was carried out with $50 \mathrm{ng}$ single-stranded cDNA in a final volume of $20 \mu \mathrm{L}$, containing $10 \mu \mathrm{L}$ of SYBR-Green Master Mix (Applied Biosystems-Life Technologies) and $250 \mathrm{nM}$ forward and reverse specific primers (Life Technologies, Supplementary Table 1), using a Real-Time 7000SDS Termocycler (Applied Biosystems-Life Technologies), with denaturation at $95{ }^{\circ} \mathrm{C}$ for $10 \mathrm{~min}, 40$ cycles of 15 seconds at $95{ }^{\circ} \mathrm{C}$ and $1 \mathrm{~min}$ annealing and extension at $60{ }^{\circ} \mathrm{C}$. Gene expression was quantified by using the relative $2-\Delta \Delta \mathrm{Ct}$ method (Livak \& Schmittgen, 2001), and the glyceraldehyde 3-phosphate dehydrogenase gene (GAPDH ) as reference (Montero-Palmero et al., 2013).

\section{Glutathione reductase in gel activity}

GR enzymatic activities were determined in gel after separation of protein extracts using non-denaturing polyacrylamide electrophoresis (Sobrino-Plata et al., 2009). Protein loading was 20 and $10 \mu \mathrm{g}$ for shoot and root samples, respectively. The staining solution was $250 \mathrm{mM}$ Tris-HCl buffer, $\mathrm{pH} 7.5$, supplemented with $0.2 \mathrm{mg} \mathrm{mL}^{-1}$ thizolyl blue tetrazolium bromide, $0.2 \mathrm{mg} \mathrm{mL}^{-1} 2,6$-dichlorophenol indophenol, $0.5 \mathrm{mM} \mathrm{NADPH}$ and $3.5 \mathrm{mM}$ GSSG.

\section{Western-blot immunodetection}

Immunodetection was performed by Western-blot after denaturing gel electrophoresis (Laemmli, 1970) and blotting onto a nitrocellulose membrane (BioTrace?NT Pall Corporation, East Hills, NY, USA), using a semi-dry procedure (Trans Blot? SD Semi-Dry Electrophoretic Transfer Cell; BioRad, Hercules, CA, USA). Membranes were incubated overnight at $4^{\circ} \mathrm{C}$ with the primary antibodies ( $\alpha$-GR (AS06 181), dil. 1/5000; $\alpha$ gECS (AS06 186), dil. 1/2500 (Agrisera, Vännäs, Sweden). After incubation with the anti-rabbit secondary antibody linked to horse radish peroxidase (HRP), proteins were detected using the LumiSensor Chemiluminescent HRP Substrate Kit (GenScript, Piscataway, NJ, USA), and images were taken with a ChemiDoc XRS+ System (BioRad). 


\section{Xylem sap extraction and collection}

Plants were collected and roots rinsed with distilled water, then excised at the caulinar (floral) stem above the rosette leaves, and the xylem sap was collected directly from the cut with a micropipette. To improve xylem sap exudation in Hg-stressed plants, roots were subjected to external pressure in a portable SKPM 1400 Scholander pressure chamber (SKYE Instruments Ltd., Powys, UK) by applying a 3 MPa constant pressure with compressed $\mathrm{N}_{2}$ gas for less than $20 \mathrm{~min}$. The first $10 \mu \mathrm{L}$ were discarded to avoid cellular contamination, and the xylem sap collected $(45 \mu \mathrm{L})$ was transferred to Eppendorf tubes containing $5 \mu \mathrm{L}$ of acid mixture (10\% metaphosphoric acid, $1 \%$ formic acid and $10 \mathrm{mM}$ EDTA), for preservation of biothiol and biothiol$\mathrm{Hg}$ complexes. Samples were subsequently frozen at $-80^{\circ} \mathrm{C}$ and stored until analysis. Cross-contamination with cellular and phloem exudates was checked routinely by measuring L-malate dehydrogenase (c-MDH) activity (López-Millán, Morales, Abadıa, \& Abadıa, 2000) (see Extended Materials and Methods details in Supplementary online material).

\section{Analysis of biothiols by HPLC-DAD}

Biothiols in shoots and roots were analysed by HPLC-UV-diode array detector (DAD) (Sobrino-Plata et al., 2009). Extracts $(100 \mu \mathrm{L})$ were injected in a Mediterranea SEA18 column $(5 \mu \mathrm{m}, 250$ x $4.6 \mathrm{~mm}$; Teknokroma, San Cugat del Vallés, Spain), using a 1200 HPLC system (Agilent), and biothiols were detected after postcolumn derivatization with Ellman reagent. Quantification was carried out adding N-acetyl cysteine (NAcCys; final concentration $250 \mu \mathrm{M}$ ) as internal standard prior to sample homogenization.

\section{Analysis of biothiols and ascorbate by HPLC-ESI-MS(TOF)}

Ascorbate, biothiols and Hg-biothiol complexes were analysed by HPLC-electro spray ionisation (ESI)time-of-flight mass spectrometry [MS(TOF)], using an HPLC system (Alliance 2795, Waters, Milford, MA, USA), equipped with a reverse-phase monolithic UPLC column (Mediterranea SEA18 $3 \mu \mathrm{m} 15$ x $0.21 \mathrm{~cm}$, Teknokroma), and coupled to a MS-TOF spectrometer (MicrOTOF, Bruker Daltonics, Bremen, Germany) equipped with an ESI source (Carrasco-Gil et al. , 2011), with a mobile phase made with solvents A $(0.1 \%$ formic acid in miliQ water), and B (0.1\% formic acid in acetonitrile)(see Extended Materials and Methods details in Supplementary online material). After chromatographic separation, sample was directed with a flow rate of $200 \mu \mathrm{L} \mathrm{min}{ }^{-1}$ to the ESI interface. The MS(TOF) operated in negative/positive ion mode at $-500 / 4500 \mathrm{~V}$ endplate and spray tip voltages, respectively. The orifice voltage was set at $100 \mathrm{~V}$ and full scan data acquisition was carried out from $\mathrm{m} / z$ 50 to1000. The mass axis was calibrated externally using Li-formate adducts $(10 \mathrm{~mm} \mathrm{LiOH}, 0.2 \%$ (v/v) formic acid and $50 \%$ (v/v) 2-propanol). The HPLC-ESIMS(TOF) system was controlled with MicrOTOF Control v.2.2 and HyStar v.3.2, and data were managed with Data Analysis v.3.4 (software packages from Bruker Daltonics). Ion chromatograms were extracted with a precision of $0.05 \mathrm{~m} / \mathrm{z}$ units.

\section{MS/MS for $\mathrm{HgPC}_{2}$ complex analysis}

For LC-MS ${ }^{n}$ measurements the same HPLC system described above is used, including chromatographic column and analysis conditions, but the MSn study was performed using a HCT Ultra high-capacity ion trap (Buker Daltonics). ESI conditions were as described previously and to establish the optimum $\mathrm{MS}^{n}$ conditions, standard solutions of $\mathrm{HgPC}_{2}$ were tested. A volume of $20 \mu \mathrm{L}$ of standard or xylem sap samples was injected into the LC system and $\mathrm{MS}^{n}$ analysis were controlled by HyStar v 3.2 software (Bruker Daltonics). MS ${ }^{n}$ experiments were conducted by selecting the high intensity peak mother ion $(740.1 \mathrm{~m} / z$ for MS, and 536.1

$m / z$ for $\mathrm{MS}^{2}$ ) at the retention time of the compound chromatographic peak, and data were collected in total ion counting mode, acquiring the spectra in the range 100-1100 $\mathrm{m} / z$.

\section{Statistics}

Statistical analysis was performed with SPSS for Windows (v. 19.0), using an ANOVA with Tuckey test. Results shown are means of at least three replicates \pm standard deviation, using $p<0.05$ to detect statistically significant differences. 


\section{RESULTS}

Biothiol concentrations in roots and shoots varied greatly depending on Arabidopsis genotypes according to the HPLC-DAD analysis (Fig. 1; Supplementary Table 2). Glutathione was present in all genotypes, but it was at remarkably low concentrations in the $\gamma$ ECS mutants cad2-1, pad2-1 and rax1-1, when compared with the levels of the wild type Col-0 (all mutants were unequivocally identified by PCR amplification and sequence alignment; Supplementary Fig. 3). In the phytochelatin-defective mutant cad1-3, the GSH concentration in shoots was almost 2-fold compared with the wild-type. In the presence of $3 \mu \mathrm{M} \mathrm{Hg}, \mathrm{PC}_{2}$ $\left((\gamma \text { Glu-Cys })_{2}\right.$-Gly $), \mathrm{PC}_{3}\left((\gamma \text { Glu-Cys })_{3}\right.$-Gly $)$ and $\mathrm{PC}_{4}\left((\gamma \text { Glu-Cys })_{4}\right.$-Gly $)$ were found in Col-0 roots, whereas only $\mathrm{PC}_{2}$ and $\mathrm{PC}_{3}$ appeared in rax1-1 roots. However, none of those $\mathrm{PCs}$ were observed in cad2-1 and pad2-1 mutants. As expected, we could not detect PCs in cad1-3 under $\mathrm{Hg}$ stress, in spite of the fact that GSH concentrations were the highest observed both in shoots and roots, doubling the concentration found in Arabidopsis Col-0 (Fig. 1; Supplementary Table 2) .

The decrease of GSH levels in pad2-1, cad 2-1 andrax1-1 and the inability to synthesize PCs in cad1-3 were accompanied by significant changes in ascorbic acid (ASA), reduced (GSH) and oxidized glutathione (GSSG) concentrations, as measured by HPLC-ESI-MS(TOF) (Table 1). Arabidopsis mutants treated with $3 \mu \mathrm{M} \mathrm{Hg}$ had ASA concentrations in roots well above of values found in Col-0, which almost doubled in shoots. On the other hand, GSH concentrations followed the same pattern found using HPLC-DAD, with pad2-1, cad2-1 and rax1-1 having the lowest values both in roots and shoots, whereas the GSH concentration in cad1-3 was 2-fold higher than Col-0. Exposure to $3 \mu \mathrm{M} \mathrm{Hg}$ led to general increases in GSH concentrations in shoots and roots of all mutant genotypes, effect particularly intense in cad1-3. With respect to GSSG, concentrations were one order of magnitude lower than those of GSH, but they changed with a similar pattern. As a result, there were minimal changes in the relative content of GSSG irrespective of genotype and occurrence of $\mathrm{Hg}$ stress.

The marked changes in ASA and GSH/GSSG contents observed in response to Hg suggested possible alterations in the redox balance of mutant shoots and roots. We firstly analysed the concentrations of $\mathrm{Hg}$ in shoots and roots of Arabidopsis, which accumulated largely in roots (shoots Hg concentrations was less than $1 \%$ of that found in roots; Fig. 2a). All $\gamma$ ECS mutants had similar Hg levels in roots, which were approximately $50 \%$ of the concentration found in Col-0 and cad1-3plants (Fig. 2a). However, Hg concentrations in shoots were not statistically different between genotypes. In parallel, we determined chlorophyll fluorescence parameters, and observed that non-photochemical quenching was severely impaired in $\gamma \mathrm{ECS}$ and PCS mutant genotypes both in control and $3 \mu \mathrm{M}$ Hg-treated plants (Fig. 2b), confirming that limiting biothiols metabolism led to stress in leaves. GR activity, an enzyme specifically sensitive to this $\mathrm{Hg}$ (Sobrino-Plata et al. 2009), was not affected in roots (Fig. 3a), but was impaired by $\mathrm{Hg}$ in Col-0 andcad1-3 roots with an almost complete inhibition in cad2-1, pad2-1, and rax1-1 mutants (Fig. 3a). Despite such inhibition, the amount of GR protein did not change appreciably in shoots and roots even under Hg-stress independently of the genotype (Fig. 3b). With regard to $\gamma \mathrm{ECS}$ in shoots, protein accumulation under control conditions was remarkably lower (40-50\%) in rECS andcad1-3 mutants than in Col-0. Mercury stress also led to a marked decrease in Col-0 leaves, reaching similar values in all genotypes (Fig. 3b). However, there were no differences among genotypes and Hg stress levels in root $\gamma \mathrm{ECS}$, probably due to the low signal obtained by $\alpha-\gamma$ ECS immunodetection (high background; Fig. 3b).

Our previous study established that part of the ability of plants to withstand $\mathrm{Hg}$ toxicity depends on the formation of $\mathrm{Hg}$-PCs complexes, such as $\mathrm{HgPC}_{2}\left(\mathrm{Hg}(\gamma \text { GluCys })_{2} \mathrm{Gly}\right)$ and $\mathrm{HgPC}_{3}\left(\mathrm{Hg}(\gamma \text { GluCys })_{3} \mathrm{Gly}\right)$ (Carrasco-Gil et al., 2011). Full HPLC-ESI-MS(TOF) analysis of biothiol ligands and Hg-biothiol complexes (Hg-PCs) in shoots and roots of showed clear differences between all studied Arabidopsis genotypes (Fig. 4). In shoots, we could only detect free $\mathrm{PC}_{2}\left(\left[\mathrm{PC}_{2}-\mathrm{H}\right]^{-} ; m / z\right.$ 538.1) and $\mathrm{PC}_{3}\left(\left[\mathrm{PC}_{3}-\mathrm{H}\right]^{-} ; m / z\right.$ 770.2) ligands, whereas in roots there were oxidized variants of free PCs, such as $\left(\left[\mathrm{PC}_{3} \mathrm{Oxd}-\mathrm{H}\right]^{-} ; m / z\right.$ 768.2), $\mathrm{Hg}-\mathrm{PC}$ complexes like $\mathrm{HgPC}_{2}\left(\left[\mathrm{HgPC}_{2}-\mathrm{H}\right]^{-} ; m / z\right.$ 738.1) and $\mathrm{HgPC}_{3}\left(\left[\mathrm{HgPC}_{3}-\mathrm{H}\right]^{-} ; m / z\right.$ 970.1). The graphical table included in Fig. 4b shows the groups of free ligands, oxidised PCs and Hg-biothiol complexes, found in shoots and roots of all Arabidopsis genotypes. The results in rax1-1 and cad2-1 roots closely resembled those found for Col-0, 
where we detected $\left[\mathrm{HgPC}_{2}-\mathrm{H}\right]^{-}$and $\left[\mathrm{HgPC}_{3}-\mathrm{H}\right]^{-}$, albeit with a rather weak signal (data not shown). On the other hand, in pad2-1 we only found GSH $\left([\mathrm{GSH}+\mathrm{H}]^{+} ; m / z 308.1\right)$ and GSSG $\left([\mathrm{GSSG}+\mathrm{H}]^{+} ; m / z\right.$ 613.3) in roots and shoots, which were better detected in positive mode, in addition to $\mathrm{PC}_{2}$, that was just over the background signal. As expected, cad1-3 did not accumulate free PCs or Hg-PCs complexes.

Recent studies indicated that toxic elements (Cd and As) are chelated with PCs in roots impeding translocation to shoots and potentially helping plants to attenuate stress, in a manner that metal(loid)-PCs complexes would mass in root vacuoles (Liu et al., 2010; Mendoza-Cózatl et al., 2008) However, to some extent metal(loid)s may travel to shoots bound to organic ligands such as PCs (Shi et al., 2019). To determine whether Hg had a similar behaviour, we studied the possible occurrence of biothiols and Hg-PCs complexes in xylem sap by HPLC-ESI-MS(TOF) using both positive and negative modes. Since Hg blocks water movement through plant vascular tissues, we used a Schölander pressure chamber to generate sufficient root pressure to impulse xylem water movement. All xylem sap samples were checked for phloem or broken cells fluids contamination by measuring $\mathrm{MDH}$ activity, which indicated that cross-contamination was negligible in all Arabidopsis genotypes under Hg stress (Supplementary Fig.3). The compounds GSH $\left([\mathrm{GSH}+\mathrm{H}]^{+} ; m / z\right.$ 308.1) and GSSG $\left([\mathrm{GSSG}+\mathrm{H}]^{+} ; m / z\right.$ 613.3) appeared in the xylem sap of all genotypes, albeit signals were lower in $\gamma$ ECS mutants (data not shown). The characteristic $\mathrm{PC}_{2}$ peak $\left(\left[\mathrm{PC}_{2}+\mathrm{H}\right]^{+} ; m / z 540.1\right)$ appeared in xylem sap of Col-0 and, at very low intensity, also in rax1-1 (Fig. 5). This compound coeluted with another of $m / z$ 538.1, which was tentatively identified as oxidized $\mathrm{PC}_{2}\left(\mathrm{PC}_{2}\right.$ oxd $)$. However, $\mathrm{PC}_{2}$ or $\mathrm{PC}_{2}$ oxd were not detected incad2-1, pad2-1 and, as expected, PCS mutant cad1-3 .

To confirm the nature of $\mathrm{PC}_{2}$ oxd we run in parallel a hydroponic experiment with Col-0 Arabidopsis treated with $10 \mu \mathrm{M} \mathrm{Cd}$ for $72 \mathrm{~h}$. In this case, we got a better signal in MS(TOF) in negative mode with a $\mathrm{m} / z$ $536.1\left(\left[\mathrm{PC}_{2} \mathrm{Oxd}-\mathrm{H}\right]^{-}\right)$(Supplementary Fig. 4a); molecular ion that was subjected to tandem MS (-MS ${ }^{2}$ ), and was compared with those obtained using $\mathrm{PC}_{2}\left(\mathrm{~m} / z\right.$ 538.13) and $\mathrm{PC}_{2}$ oxd $(\mathrm{m} / z$ 536.1) standards, which had characteristic daughter ions at $m / z 254.1$ and 128.0 (Supplementary Fig. 4c). Incidentally, we were unable to observe any Cd-PC complex, in spite of using ESI-MS(TOF) settings appropriate for detection of $\mathrm{CdPC}_{2}$, as we obtained the characteristic peaks associated with the natural $\mathrm{Cd}$ isotopic distribution (major $\left[\mathrm{CdPC}_{2}-\mathrm{H}\right]^{-}$ peak at $m / z 650.0$ ) by direct injection of a $\mathrm{Cd}: \mathrm{PC}_{2}$ standard (Supplementary Fig. $4 \mathrm{~b}$ ).

In Col-0 xylem sap, along with to $\mathrm{PC}_{2}$ and $\mathrm{PC}_{2}$ oxd we found only a compound with the characteristic $\mathrm{Hg}$ isotopic fingerprint that could correspond to $\mathrm{Hg}$-PCs complexes, which was tentatively assigned to $\mathrm{HgPC}_{2}$, eluting separately from free biothiol ligands (Fig. 5a). The MS(TOF) spectrum (in positive mode) of the detected compound $\left(\left[\mathrm{HgPC}_{2}+\mathrm{H}\right]^{+} ; m / z\right.$ 740.1) fitted well with theoretical data and also with a $\mathrm{Hg}: \mathrm{PC}_{2}$ standard mixture (1:1) (Fig. 5b). The identity of the $m / z 740.1$ ion peak of Col-0 xylem samples was confirmed using tandem MS/MS analysis. The same $\mathrm{Hg}: \mathrm{PC}_{2}$ standard mixture was used to set up analytical conditions, and the $m / z 740.1$ mother ion was selected and sent to the collision cell for fragmentation $\left(\mathrm{MS}^{2}\right)$. Several major daughter ions appeared with $m / z$ 609.1, 536.1 and 508.1 both in the $\mathrm{HgPC}_{2}$ standard and the Col-0 xylem sap (Fig. 5c). Some of these ions were tentatively identified by comparing with those detected in Hg-biothiol complexes analysis as follows: $m / z 609.1$ was assigned to $\left[\mathrm{HgPC}_{2}-\mathrm{Glu}\right]^{+} ; m / z 536.1$ matched $\left[\mathrm{PC}_{2} \text { oxd-2H }\right]^{+}$, and $m / z 508.1$ was assigned to $[\mathrm{HgGSH}+\mathrm{H}]^{+}$. Further identification of the $m / z 536.1$ ion, with the highest intensity peak, was obtained after a second fragmentation $\left(\mathrm{MS}^{3}\right)$ resulting in various ions. The $\mathrm{MS}^{3}$ spectra of both the xylem sap and the standard mixture were also very similar, with a major $\mathrm{m} / z 507.1$ daughter ion (possibly [GSH-H] ${ }^{+}$), with a second $m / z 489.1$ ion also present in both samples (Fig. $5 \mathrm{~d}$ ). Therefore, we can assert that $\mathrm{HgPC}_{2}$ complexes could be transferred from roots to shoots via xylem flux, process that did not occur in rax1-1, cad2-1 and cad1-3 mutants. Nevertheless, we could not determine to what extent $\mathrm{Hg}$ flows to shoots via xylem, since our ICP-MS analysis failed to detect $\mathrm{Hg}$ above background levels, probably due to the small volume of sample collected $(10-50 \mu \mathrm{L})$.

In view of the relevant role that biothiol metabolism has in tolerance to $\mathrm{Hg}$ and $\mathrm{Hg}$ speciation in plants, we analysed the expression pattern of 20 genes involved in sulphur uptake, assimilation and incorporation to biothiols under Hg-stress (Gigolashvili \& Kopriva, 2014). The expression pattern was organ-dependent, with some genes being over-expressed in the shoots of certain mutants treated with Hg (Fig. 6), whereas in 
the roots we only detected gene down-regulation under $\mathrm{Hg}$ stress (Fig. 7). Regarding transcription factors in shoots, MYB28 was induced only in the $\gamma$ ECS-mutants cad2-1 and pad2-1 under Hg exposure, whereas MYB51 was suppressed in rax1-1. On the other hand, both MYB28 and MYB51 were down-regulated in roots under Hg-stress, especially in rax1-1 andcad1-3 mutants (Fig. 7). We also found significant downregulation of SLIM1 in roots of all mutant Arabidopsisgenotypes (Fig. 7; Suppl. Tables 3 and 4).

Among the genes involved in sulphur incorporation and assimilation in shoots, the sulphur transporter SULTR1;2 had the highest over-expression in Hg-treated cad2-1, rax1-1 andcad1-3 plants, whereas a strong repression was observed in Col-0 (Fig. 6; Suppl. Table 3). A similar repression appeared in Col-0 for ATP sulphurylase (ATPS3 ) and APS reductase (APR1 andAPR3) (Fig. 6). On the other hand, ATPS4 (only inpad2-1), APR1, APR2 and APR3 (only inrax1-1), were over-expressed in pad2-1, rax1-1 andcad1-3 plants treated with $3 \mu \mathrm{M} \mathrm{Hg}$. With regard to GSH and PCs metabolism, we only observed a minor down-regulation under $\mathrm{Hg}$ stress, particularly significant for cad2-1 and pad2-1 O-acetylserine (thiol) lyase (OASTLA and OASTLB ) genes. Interestingly, expression of the phytochelatin synthase genesPCS1 and PC2 decreased in leaves in Hg-treated plants, being particularly significant in pad2-1, rax1-1 andcad 1-3 (Fig. 6, Supplementary Table 3). Finally, in roots under $\mathrm{Hg}$ stress we only observed significant gene down-regulation, mostly in the mutant genotypes. Especially relevant was the down-regulation of sulphate transporters, including a remarkable decrease forSULTR1;2 in cad2-1, $\operatorname{rax1-1}$ and cad1-3 (Fig. 7). The expression of other sulphur transporters decreased, including that of SULTR2;1 in rax1-1 and cad1-3, andSULTR3;5, which was very intense in all $\mathrm{Hg}$-exposedArabidopsis genotypes. With regard to sulphur assimilation genes, the most consistent changes occurred in cad1-3, whereATPS1, ATPS3 , SiR, OASTLB , OASTLC , $\gamma E^{\circ} \Sigma, G S H-S, P C S 1$ and PCS2 expression decreased in plants treated with $3 \mu \mathrm{M} \mathrm{Hg}$ (Fig. 7, Supplementary Table 4).

\section{DISCUSSION}

Knock-down of $\gamma$ ECS resulted in a drastic limitation of biothiol concentrations under control and Hg-stress conditions, particularly in the cad2-1 and pad2-1 mutants (Fig. 1), confirming previous results in these GSH-depleted genotypes (Parisy et al., 2007; Ball et al., 2004; Cobbett, 2000) and in Arabidopsis leaf discs and plants treated with similar doses of $\mathrm{Hg}$ and $\mathrm{Cd}$ (Sobrino-Plata et al., 2014a; 2014b). Interestingly, the mildly-affected knock-down rax1-1 $\gamma$ ECS mutant treated with $3 \mu \mathrm{M} \mathrm{Hg}$ also accumulated $\mathrm{PC}_{2}$ and $\mathrm{PC}_{3}$ (but not $\mathrm{PC}_{4}$ ) in roots, but to a lower extent than did wild-type plants as observed in Cd-treated plants (Sobrino-Plata et al., 2014b). We were unable to detect PCs in shoots, organs that accumulated much less $\mathrm{Hg}$ than roots (by two orders of magnitude), since a certain $\mathrm{Hg}$ concentration threshold may be required to trigger synthesis of PCs. In fact, numerous PCs appeared in Col-0 and rax1-1 leaf discs subjected to direct infiltration with 3 and $30 \mu \mathrm{M} \mathrm{Hg}$; behaviour that was accentuated at longer exposure times $(48 \mathrm{~h})$ when $\mathrm{PC}_{2}$ and $\mathrm{PC}_{3}$ also appeared in cad2-1 (Sobrino-Plata et al., 2014a). On the other hand, the inability to synthesize PCs incad1-3 led to a significantly higher GSH accumulation in when compared to Col-0 (Fig. 1, Table 1). Interestingly, this increase became larger under $\mathrm{Hg}$ stress, in agreement with our previous observations incad1-3 leaf discs infiltrated with $3 \mu \mathrm{M} \mathrm{Hg}$ for $24 \mathrm{~h}$ (Sobrino-Plata et al., 2014a). It has been proposed recently that PCS functions as a transpeptidase important for GSH and conjugated GSH turnover, which may explain the high GSH levels found in cad1-3plants (Kühnlenz, Westphal, Schmidt, Scheel, \& Clemens, 2015).

Depletion of GSH resulted in the elicitation of a severe oxidative stress with $3 \mu \mathrm{M} \mathrm{Hg}$, with a marked inhibition of GR activity in the roots of $\gamma$ ECS mutants in comparison with Col-0 and cad1-3, without any changes in enzyme amount (Fig. 3). The mutant cad1-3lacked the ability to form Hg-PC complexes, but the Hg-induced damage was similar to that found in Col-0, possibly due to enhanced GSH levels in this mutant. Strong GR inhibition occurred in roots of cad2-1 ,pad2-1 and rax1-1 treated with $10 \mu \mathrm{M} \mathrm{Hg}$ for $72 \mathrm{~h}$, which also suffered extensive alterations in membrane proteins (i.e., degradation of $\mathrm{H}^{+}$-ATPase and strong inhibition of NADPH-oxidase; Sobrino-Plata et al., 2014b). The GR inhibition appears to be triggered specifically by $\mathrm{Hg}$ over certain concentrations inMedicago sativa or Silene vulgaris, whereas other toxic elements usually lead to an enhanced activity (Sobrino-Plata et al., 2013; 2009), as can be used as a marker of 
Hg-stress. Besides the strong GR inhibition, there were minor and non-consistent changes in the proportion of GSSG in the analysed Arabidopsis genotypes (Table 1). This concurs with the minimal oxidation of homoglutathione (hGSH) (less than 15\%) found in $30 \mu \mathrm{M}$ Hg-treated alfalfa seedlings (Ortega-Villasante et al., 2007). Therefore, even though GSH synthesis was compromised in $\gamma E C S$ mutants, much severe and chronic cellular damage would be required to observe relevant GSH oxidation. On the other hand, the poorer tolerance to $\mathrm{Hg}$ caused by limited GSH also led to alterations of chlorophyll fluorescence parameters, with a remarkable NPQ decrease (Fig. 2), in accordance with results obtained in Arabidopsistreated with $\mathrm{Hg}, \mathrm{Cd}$ and $\mathrm{Cu}$ over $72 \mathrm{~h}$ (Maksymiec, Wójcik, \& Krupa, 2007; Sobrino-Plata et al., 2014a). GSH plays a central role in chloroplast redox balance, keeping ASA and xanthophyll pools reduced at optimal levels to sustain NPQ under stress (Yin et al., 2010), which may be hampered in $\gamma E C S$ mutants. Interestingly, the increase in ASA shoot concentrations under $\mathrm{Hg}$ stress was particularly intense in $\gamma \mathrm{ECS}$ mutant genotypes. Similar response was found in Cd-treated cad2-1 mutants, where ASA concentration was higher than in wildtype plants, particularly in roots (Jozefczak et al., 2015). In this respect, recent experiments showed that increases in ASA concentrations are a common response of plants to metal stress, especially in shoots where this antioxidant metabolite helps protecting the photosynthetic apparatus, which may be hampered by both the lack of GSH and the oxidative stress induced by Hg (Bielen, Remans, Vangronsveld, \& Cuypers, 2013).

Mercury is thought to bind strongly to cell walls of epidermal and xylem root cells, possibly bound to the Cys thiol residues of proteins, thus preventing translocation to shoots (Carrasco-Gil et al., 2011; 2013), as found in roots of different plant species (Carrasco-Gil et al., 2011; Sobrino-Plata et al., 2009; 2013; 2014b). Interestingly, $\gamma \mathrm{ECS}$ mutants roots had significant lower $\mathrm{Hg}$ concentration than Col-0, with no effects in shoots, whereas stronger Hg-induced damages appeared in the mutants. Similarly, metal accumulation in shoots did not change in Cd- and Hg-treated cad2-1 plants (Li, Dankher, Carreira, Smith, \& Meagher, 2006), in line with the view that cellular biothiol levels have little impact on overall plant metal distribution (Lee et al., 2003). On the other hand, it is known that transpiration is strongly impaired by $\mathrm{Hg}$ (Moreno, Anderson, Stewart, \& Robinson, 2008), a toxic metal that drastically reduces metabolic-driven water conductance in roots (Lovisolo, Tramontini, Flexas, \& Schubert, 2008). Toxic effect that impelled us to use the Schölander pressure chamber to collect enough xylem sap under Hg stress, particularly in $\gamma$ ECS mutant plants. Therefore, it is feasible that the strong Hg-stress in $\gamma E C S$ mutants caused poorer water flow to shoots, limiting $\mathrm{Hg}$ uptake and translocation to the aerial part of Hg-exposed plants.

Xylem conforms, along with phloem, the major long-distance transport system for movement and distribution of water, ions and metals throughout the plant (Álvarez-Fernández et al., 2014). Cadmium transport by the xylem determines $\mathrm{Cd}$ accumulation in shoots, which depends on loading driven by metal transporters (Wu et al., 2015), while biothiols have been suggested as long distance carriers for $\mathrm{Cd}$ in the phloem of Brassica napus (Mendoza-Cózatl et al., 2008). The high stability of $\mathrm{Hg}-\mathrm{PC}$ complexes found in plant roots could provide a basis for $\mathrm{Hg}$ long-distance transport, as it was suggested by the association of $\mathrm{Hg}$ with sulphur in stems and leaf veins of alfalfa plants exposed to $\mathrm{Hg}$ (Carrasco-Gil et al., 2013). HPLC-ESI-MS(TOF) analysis revealed for the first time that $\left[\mathrm{HgPC}_{2}-\mathrm{H}\right]^{+}$indeed occurs in the xylem sap of Col-0 (Fig. 5), identity that was confirmed by $\mathrm{MS}^{\mathrm{n}}$ analysis, with daughter molecular ions in the $\mathrm{MS}^{2}$ and $\mathrm{MS}^{3}$ spectra matching those of standards. We also detected free $\left[\mathrm{PC}_{2}-\mathrm{H}\right]^{-}$and $\left[\mathrm{PC}_{2} \mathrm{Oxd}-\mathrm{H}\right]^{-}$in xylem sap, confirming our preliminary findings in the xylem sap of Col-0 plants treated with $10 \mu \mathrm{M}$ Cd for $72 \mathrm{~h}$ (Supplementary Fig. 2). Oxidised $\mathrm{PC}_{2}$ was also found in the xylem sap of Brassica napus plants subjected to Cd (Mendoza-Cózatl et al., 2008) and Arabidopsis seedlings treated with As (Liu et al., 2010), but metal(loid)-PC complexes were not found in those cases. Moreover, a very low concentration of As was found in xylem sap of the metallophyte castor bean, which was accompanied again with oxidised GSH and $\mathrm{PC}_{2}$ (Ye et al., 2010), probably as a result of the oxidative stress and redox imbalance triggered by metal(loid)s. As(III)- and Cd-biothiols complexes may be less stable than those formed with $\mathrm{Hg}$ in our conditions, able to withstand even acidic extraction.

Plants treated with metals experience alterations in sulphate uptake and assimilation (Na \& Salt, 2011; Nocito et al., 2006), which prompted us to analyse the expression of twenty genes involved in the sulphur assimilatory pathway under $\mathrm{Hg}$-stress. Our results revealed in all $A$. thaliana genotypes tested different responses to $\mathrm{Hg}$ in roots and shoots, indicating that both organs had independent stress responses as found with 
other metals (Jozefczak et al., 2014). In general, we observed a modest response of genes with fold-changes generally not larger than three (significant at $p<0.05$ ), following the same pattern of recent transcriptomic analyses performed after short-term $\mathrm{Hg}$ treatments in Medicago (Montero-Palmero et al., 2013; Zhou et al., 2013), barley (Lopes et al., 2013), rice (Chen et al., 2014) and tomato (Hou, Liu, Wang, Zhao, \& Cui, 2015).

With regard to sulphur metabolism regulation, several transcription factors have been reported to be overexpressed under S-starvation, such as the central hub SLIM1 regulator and several R2R3-MYBs, including MYB28 and MYB51 (Frerigmann \& Gigolashvili, 2014). However, we only observed MYB28 upregulation in cad2-1 and pad2-1 shoots under Hg stress. Incidentally, a rice R2R3-MYB (OsARM1) has been found to be upregulated in stems and leaves upon As exposure (Wang et al., 2017), and several R2R3-MYBs control response to Cd-stress viaABA signalling (Zhang et al., 2019). However, we found marked MYB28, MYB51 and SLIM1 down-regulation in roots of Hg-stressed $\gamma$ ECS andcad1-3 Arabidopsis mutants, which can likely explain the low expression of several sulphur assimilatory pathway genes. Little is known about how SLIM1 may operate under abiotic stress, which may undergo post-transcriptional redox imbalance regulation occurring in Hg-treated $\gamma$ ECS mutants (Koprivova \& Kopriva, 2014).

Sulphate uptake is a bottleneck in plant sulphur incorporation, which were upregulated under metal stress, such as SULTR1;1 in roots of maize (Nocito et al., 2006) and Arabidopsis (Ferri et al., 2017). However, other members of the SULTR transporter gene family in Chinese cabbage plantlets and sorghum responded in different manner in leaves and roots under metal stresses (Shahbaz et al., 2014; Akbudak, Filiz, \& Kontbay, 2018). We found that sulphate transporter SULTR1;2 was up-regulated in shoots in Arabidopsis $\gamma$ ECS and PCS mutants under Hg-stress, response was also found for SULTR3;5 in roots ofMedicago just after $6 \mathrm{~h}$ exposure to $3 \mu \mathrm{M} \mathrm{Hg}$ (Montero-Palmero et al., 2013). Conversely, SULTR1;2 was down-regulated in shoots of Col-0 and roots of all Arabidopsis mutants, following the same pattern of SULTR2;1 and SULTR3;5 (Figs. 6,7), in agreement with the short-term down regulation of SULTR3;3 in rice seedlings treated with $25 \mu \mathrm{M} \mathrm{Hg}$ for $3 \mathrm{~h}$ (Chen et al., 2014). Cadmium exposure and sulphate limitation revealed differences in the transcriptional control of three sulphate transporter (SULTR1;2) genes in Brassica juncea (Lancilli et al., 2014). Similarly,SULTR1 and SULTR2 expression decreased in roots and shoots of Cd-treated Arabidopsis at high Cd doses (over $40 \mu \mathrm{M}$ ) (Yamaguchi et al., 2016). Therefore, SULTR expression under metal stress changed depending on the plant organ, supplied metal and doses, implying a complex regulation and specific responses. Time-course experiments to monitor the metal induced expression of SULTR1;2showed that in roots it peaked a few hours after metal exposure but subsided subsequently (Jobe et al., 2012). It is feasible that the GSH depletion promoted SULTR1;2 expression in shoots under Hg stress, where we observed significant redox alterations, whereas under acute cellular damage there might be a general transcriptional down-regulation in roots (Montero-Palmero et al., 2013).

APRs are key enzymes of sulphur assimilatory pathway, that produce sulphite from adenosine 5' phosphosulphate (Kopriva, 2006), genes that were up-regulated in Arabidopsis $\gamma$ ECS and PCS mutants shoots treated with $\mathrm{Hg}$, in agreement with the overexpression found in short-term Hg-treated Medicago (Montero-Palmero et al., 2013). However, the rest of S-assimilatory pathway genes in shoots and roots of $\gamma \mathrm{ECS}$ and PCS mutants were modestly affected or down-regulated by $\mathrm{Hg}$ (Figs. 6, 7). It must be emphasized that until now none of the transcriptomic analyses carried out in plants treated with $\mathrm{Hg}$ showed significant changes in gene expression of enzymes involved in Cys, $\gamma \mathrm{EC}$, GSH or PCs synthesis (Chen et al., 2014; Hou et al., 2015; Lopes et al., 2013; Montero-Palmero et al., 2013; Zhou et al., 2013). In consequence, despite the several significant changes in S-assimilatory gene expression, occurring mainly in GSH deprived plants, we cannot rule out that the process can be post-transcriptionally controlled. Several stress hormones and the redox cellular balance can contribute to altered enzymatic activities that modify biothiol pools (Kopriva et al., 2019); mechanisms that should be the matter of future research.

In conclusion, depletion of GSH led to stronger $\mathrm{Hg}$ toxicity visualised by strong inhibition of GR activity, a poor accumulation of $\mathrm{Hg}-\mathrm{PC}$ complexes and a limited translocation of $\mathrm{HgPC}_{2}$ to shoots via xylem transport. Sulphur metabolism and accumulation of biothiols help withstanding Hg-induced oxidative stress, but the mechanisms of regulation remain to be characterised in detail. Although some responses at the transcriptional 
level were detected, we cannot rule out post-transcriptional regulation, which probably play a relevant role to procure sufficient biothiols to limit $\mathrm{Hg}$ induced damage. In this sense, transcriptional sulphur-assimilation regulation could be independent of GSH cellular levels, in spite of being an essential factor to maintain the cellular redox balance that was compromised by $\mathrm{Hg}$.

\section{REFERENCES}

Akbudak, M. A., Filiz, E., \& Kontbay, K. (2018). Genome-wide identification and cadmium induced expression profiling of sulfate transporter (SULTR) genes in sorghum (Sorghum bicolor L.).BioMetals . https://doi.org/10.1007/s10534-017-0071-5

Álvarez-Fernández, A., Díaz-Benito, P., Abadía, A., López-Millán, A.-F., \& Abadía, J. (2014). Metal species involved in long distance metal transport in plants. Frontiers in Plant Science. https://doi.org/10.3389/fpls.2014.00105

Ball, L., Accotto, G. P., Bechtold, U., Creissen, G., Funck, D., Jimenez, A., Kular, B., Leyland, N., Mejia-Carranza, J., Reynolds, H., Karpinski, S., \& Mullineaux, P. M. (2004). Evidence for a direct link between glutathione biosynthesis and stress defense gene expression inArabidopsis . Plant Cell . https://doi.org/10.1105/tpc.104.022608

Bielen, A., Remans, T., Vangronsveld, J., \& Cuypers, A. (2013). The influence of metal stress on the availability and redox state of ascorbate, and possible interference with its cellular functions. International Journal of Molecular Sciences . https://doi.org/10.3390/ijms14036382

Carrasco-Gil, S., Álvarez-Fernández, A., Sobrino-Plata, J., Millán, R., Carpena-Ruiz, R. O., Leduc, D. L., \& Hernández, L. E. (2011). Complexation of $\mathrm{Hg}$ with phytochelatins is important for plant $\mathrm{Hg}$ tolerance. Plant, Cell and Environment . https://doi.org/10.1111/j.1365-3040.2011.02281.x

Carrasco-Gil, S., Siebner, H., Leduc, D. L., Webb, S. M., Millán, R., Andrews, J. C., \& Hernández, L. E. (2013). Mercury localization and speciation in plants grown hydroponically or in a natural environment.Environmental Science and Technology . https://doi.org/10.1021/es303310t

Chaney, R. L., Malik, M., Li, Y. M., Brown, S. L., Brewer, E. P., Angle, J. S., \& Baker, A. J. M. (1997). Phytoremediation of soil metals. Current Opinion in Biotechnology . https://doi.org/10.1016/S0958-1669(97)800043

Chen, Y. A., Chi, W. C., Trinh, N. N., Huang, L. Y., Chen, Y. C., Cheng, K. T., Huang, T.L., Lin, C.Y., \& Huang, H. J. (2014). Transcriptome profiling and physiological studies reveal a major role for aromatic amino acids in mercury stress tolerance in rice seedlings. PLoS ONE . https://doi.org/10.1371/journal.pone.0095163

Cobbett, C. S. (2000). Phytochelatins and their roles in heavy metal detoxification. Plant Physiology . https://doi.org/10.1104/pp.123.3.825

Ferri, A., Lancilli, C., Maghrebi, M., Lucchini, G., Sacchi, G. A., \& Nocito, F. F. (2017). The sulfate supply maximizing Arabidopsisshoot growth is higher under long- than short-term exposure to cadmium. Frontiers in Plant Science . https://doi.org/10.3389/fpls.2017.00854

Frerigmann, H., \& Gigolashvili, T. (2014). Update on the role of R2R3-MYBs in the regulation of glucosinolates upon sulfur deficiency.Frontiers in Plant Science . https://doi.org/10.3389/fpls.2014.00626

Gigolashvili, T., \& Kopriva, S. (2014). Transporters in plant sulfur metabolism. Frontiers in Plant Science . https://doi.org/10.3389/fpls.2014.00442

He, F., Gao, J., Pierce, E., Strong, P. J., Wang, H., \& Liang, L. (2015). In situ remediation technologies for mercury-contaminated soil.Environmental Science and Pollution Research . https://doi.org/10.1007/s11356015-4316-y

Hernández, L. E., Sobrino-Plata, J., Montero-Palmero, M. B., Carrasco-Gil, S., Flores-Cáceres, M. L., OrtegaVillasante, C., \& Escobar, C. (2015). Contribution of glutathione to the control of cellular redox homeostasis 
under toxic metal and metalloid stress. Journal of Experimental Botany . https://doi.org/10.1093/jxb/erv063

Hou, J., Liu, X., Wang, J., Zhao, S., \& Cui, B. (2015). Microarray-based analysis of gene expression in lycopersicon esculentum seedling roots in response to cadmium, chromium, mercury, and lead.Environmental Science and Technology . https://doi.org/10.1021/es504154y

Jobe, T. O., Sung, D. Y., Akmakjian, G., Pham, A., Komives, E. A., Mendoza-Cózatl, D. G., \& Schroeder, J. I. (2012). Feedback inhibition by thiols outranks glutathione depletion: A luciferase-based screen reveals glutathione-deficient $\gamma$-ECS and glutathione synthetase mutants impaired in cadmium-induced sulfate assimilation. Plant Journal . https://doi.org/10.1111/j.1365-313X.2012.04924.x

Jozefczak, M., Bohler, S., Schat, H., Horemans, N., Guisez, Y., Remans, T., Vangronsveld, J., \& Cuypers, A. (2015). Both the concentration and redox state of glutathione and ascorbate influence the sensitivity of Arabidopsis to cadmium. Annals of Botany . https://doi.org/10.1093/aob/mcv075

Jozefczak, M., Keunen, E., Schat, H., Bliek, M., Hernández, L. E., Carleer, R., Remans, T., Bohler, S., Vangronsveld, J., \& Cuypers, A. (2014). Differential response of Arabidopsis leaves and roots to cadmium: Glutathione-related chelating capacity vs antioxidant capacity.Plant Physiology and Biochemistry . https://doi.org/10.1016/j.plaphy.2014.07.001

Khodamoradi, K., Khoshgoftarmanesh, A. H., \& Maibody, S. A. M. M. (2017). Root uptake and xylem transport of cadmium in wheat and triticale as affected by exogenous amino acids. Crop and Pasture Science . https://doi.org/10.1071/CP17061

Kopriva, S., Malagoli, M., \& Takahashi, H. (2019). Sulfur nutrition: Impacts on plant development, metabolism, and stress responses.Journal of Experimental Botany . https://doi.org/10.1093/jxb/erz319

Kopriva, S. (2006). Regulation of sulfate assimilation inArabidopsis and beyond. Annals of Botany . https://doi.org/10.1093/aob/mcl006

Koprivova, A., \& Kopriva, S. (2014). Molecular mechanisms of regulation of sulfate assimilation: First steps on a long road. Frontiers in Plant Science . https://doi.org/10.3389/fpls.2014.00589

Krämer, U. (2005). Phytoremediation: Novel approaches to cleaning up polluted soils. Current Opinion in Biotechnology . https://doi.org/10.1016/j.copbio.2005.02.006

Kühnlenz, T., Westphal, L., Schmidt, H., Scheel, D., \& Clemens, S. (2015). Expression of Caenorhabditis elegansPCS in the AtPCS1-deficientArabidopsis thaliana cad1-3 mutant separates the metal tolerance and non-host resistance functions of phytochelatin synthases.Plant Cell and Environment . https://doi.org/10.1111/pce.12534

Laemmli, U. K. (1970). Cleavage of structural proteins during the assembly of the head of bacteriophage T4. Nature . https://doi.org/10.1038/227680a0

Lancilli, C., Giacomini, B., Lucchini, G., Davidian, J. C., Cocucci, M., Sacchi, G. A., \& Nocito, F. F. (2014). Cadmium exposure and sulfate limitation reveal differences in the transcriptional control of three sulfate transporter (Sultr1;2 ) genes in Brassica juncea.BMC Plant Biology . https://doi.org/10.1186/1471-2229$14-132$

Lee, S., Petros, D., Moon, J. S., Ko, T. S., Goldsbrough, P. B., \& Korban, S. S. (2003). Higher levels of ectopic expression of Arabidopsis phytochelatin synthase do not lead to increased cadmium tolerance and accumulation. Plant Physiology and Biochemistry . https://doi.org/10.1016/S0981-9428(03)00140-2

Li, Y., Dankher, O. P., Carreira, L., Smith, A. P., \& Meagher, R. B. (2006). The shoot-specific expression of $\gamma$-glutamylcysteine synthetase directs the long-distance transport of thiol-peptides to roots conferring tolerance to mercury and arsenic. Plant Physiology . https://doi.org/10.1104/pp.105.074815

Liu, W. J., Wood, B. A., Raab, A., McGrath, S. P., Zhao, F. J., \& Feldmann, J. (2010). Complexation of arsenite with phytochelatins reduces arsenite efflux and translocation from roots to shoots inArabidopsis . 
Plant Physiology . https://doi.org/10.1104/pp.109.150862

Livak, K. J., \& Schmittgen, T. D. (2001). Analysis of relative gene expression data using real-time quantitative PCR and the $2{ }^{\Delta \Delta^{*} \mathrm{~T}}$ method. Methods . https://doi.org/10.1006/meth.2001.1262

Lopes, M. S., Iglesia-Turiño, S., Cabrera-Bosquet, L., Serret, M. D., Bort, J., Febrero, A., \& Araus, J. L. (2013). Molecular and physiological mechanisms associated with root exposure to mercury in barley. Metallomics . https://doi.org/10.1039/c3mt00084b

López-Millán, A. F., Morales, F., Abadıa, A., \& Abadıa, J. (2000). Effects of Iron Deficiency on the composition of the leaf apoplastic fluid and xylem sap in sugar beet. Implications for iron and carbon transport. Plant Physiology . https://doi.org/10.1104/pp.124.2.873

Lovisolo, C., Tramontini, S., Flexas, J., \& Schubert, A. (2008). Mercurial inhibition of root hydraulic conductance in Vitis spp. rootstocks under water stress. Environmental and Experimental Botany . https://doi.org/10.1016/j.envexpbot.2007.11.005

Maksymiec, W., Wójcik, M., \& Krupa, Z. (2007). Variation in oxidative stress and photochemical activity in Arabidopsis thaliana leaves subjected to cadmium and excess copper in the presence or absence of jasmonate and ascorbate. Chemosphere . https://doi.org/10.1016/j.chemosphere.2006.06.025

Maxwell, K., \& Johnson, G. N. (2000). Chlorophyll fluorescence - A practical guide. Journal of Experimental Botany . https://doi.org/10.1093/jxb/51.345.659

Mendoza-Cózatl, D. G., Butko, E., Springer, F., Torpey, J. W., Komives, E. A., Kehr, J., \& Schroeder, J. I. (2008). Identification of high levels of phytochelatins, glutathione and cadmium in the phloem sap of Brassica napus . A role for thiol-peptides in the long-distance transport of cadmium and the effect of cadmium on iron translocation.Plant Journal . https://doi.org/10.1111/j.1365-313X.2008.03410.x

Montero-Palmero, M. B., Martín-Barranco, A., Escobar, C., \& Hernández, L. E. (2013). Early transcriptional responses to mercury: A role for ethylene in mercury-induced stress. New Phytologist . https://doi.org/10.1111/nph.12486

Moreno, F. N., Anderson, C. W. N., Stewart, R. B., \& Robinson, B. H. (2008). Phytofiltration of mercurycontaminated water: Volatilisation and plant-accumulation aspects. Environmental and Experimental Botany . https://doi.org/10.1016/j.envexpbot.2007.07.007

Na, G. N., \& Salt, D. E. (2011). The role of sulfur assimilation and sulfur-containing compounds in trace element homeostasis in plants.Environmental and Experimental Botany . https://doi.org/10.1016/j.envexpbot.2010.04.004

Nocito, F. F., Lancilli, C., Crema, B., Fourcroy, P., Davidian, J.-C., \& Sacchi, G. A. (2006). Heavy metal stress and sulfate uptake in maize roots. Plant Physiology . https://doi.org/10.1104/pp.105.076240

Ortega-Villasante, C., Hernández, L. E., Rellán-Alvarez, R., Del Campo, F. F., \& Carpena-Ruiz, R. O. (2007). Rapid alteration of cellular redox homeostasis upon exposure to cadmium and mercury in alfalfa seedlings.New Phytologist, https://doi.org/10.1111/j.1469-8137.2007.02162.x.

Parisy, V., Poinssot, B., Owsianowski, L., Buchala, A., Glazebrook, J., \& Mauch, F. (2007). Identification of PAD2 as a $\gamma$-glutamylcysteine synthetase highlights the importance of glutathione in disease resistance of Arabidopsis . Plant Journal . https://doi.org/10.1111/j.1365-313X.2006.02938.x

Rascio, N., \& Navari-Izzo, F. (2011). Heavy metal hyperaccumulating plants: How and why do they do it? And what makes them so interesting?Plant Science . https://doi.org/10.1016/j.plantsci.2010.08.016

Schroeder, A., Mueller, O., Stocker, S., Salowsky, R., Leiber, M., Gassmann, M., Lightfoot, S., Menzel, W., Granzow, M. \& Ragg, T. (2006). The RIN: An RNA integrity number for assigning integrity values to RNA measurements. BMC Molecular Biology . https://doi.org/10.1186/1471-2199-7-3 
Selin, N. E. (2010). Global biogeochemical cycling of mercury: A review. Annual Review of Environment and Resources . https://doi.org/10.1146/annurev.environ.051308.084314

Shahbaz, M., Stuiver, C. E. E., Posthumus, F. S., Parmar, S., Hawkesford, M. J., \& De Kok, L. J. (2014). Copper toxicity in Chinese cabbage is not influenced by plant sulphur status, but affects sulphur metabolism-related gene expression and the suggested regulatory metabolites. Plant Biology . https://doi.org/10.1111/plb.12019

Sharma, S. S., Dietz, K. J., \& Mimura, T. (2016). Vacuolar compartmentalization as indispensable component of heavy metal detoxification in plants. Plant, Cell and Environment . https://doi.org/10.1111/pce.12706

Shi, W., Zhang, Y., Chen, S., Polle, A., Rennenberg, H., \& Luo, Z. B. (2019). Physiological and molecular mechanisms of heavy metal accumulation in nonmycorrhizal versus mycorrhizal plants. Plant, Cell and Environment . https://doi.org/10.1111/pce.13471

Sobrino-Plata, J., Carrasco-Gil, S., Abadía, J., Escobar, C., Álvarez-Fernández, A., \& Hernández, L. E. (2014a). The role of glutathione in mercury tolerance resembles its function under cadmium stress in Arabidopsis . Metallomics . https://doi.org/10.1039/c3mt00329a

Sobrino-Plata, J., Meyssen, D., Cuypers, A., Escobar, C., \& Hernández, L. E. (2014b). Glutathione is a key antioxidant metabolite to cope with mercury and cadmium stress. Plant and Soil . https://doi.org/10.1007/s11104-013-2006-4

Sobrino-Plata, J., Herrero, J., Carrasco-Gil, S., Pérez-Sanz, A., Lobo, C., Escobar, C., Millán, R., \& Hernández, L. E. (2013). Specific stress responses to cadmium, arsenic and mercury appear in the metallophyteSilene vulgaris when grown hydroponically. RSC Advances . https://doi.org/10.1039/c3ra40357b

Sobrino-Plata, J., Ortega-Villasante, C., Laura Flores-Cáceres, M., Escobar, C., Del Campo, F. F., \& Hernández, L. E. (2009). Differential alterations of antioxidant defenses as bioindicators of mercury and cadmium toxicity in alfalfa. Chemosphere . https://doi.org/10.1016/j.chemosphere.2009.08.007

Tocquin, P., Corbesier, L., Havelange, A., Pieltain, A., Kurtem, E., Bernier, G., \& Perilleux, C. (2003). A novel high efficiency, low maintenance, hydroponic system for synchronous growth and flowering of Arabidopsis thaliana . BMC Plant Biology . https://doi.org/10.1186/1471-2229-3-2

Wang, F. Z., Chen, M. X., Yu, L. J., Xie, L. J., Yuan, L. B., Qi, H., Xiao, M., Guo, W., Chen, Z., Yi, K., Zhang, J., Qiu, R., Shu, W., Xiao, S., \& Chen, Q. F. (2017). OsARM1, an R2R3 MYB Transcription factor, is involved in regulation of the response to arsenic stress in rice.Frontiers in Plant Science . https://doi.org/10.3389/fpls.2017.01868

Wu, Z., Zhao, X., Sun, X., Tan, Q., Tang, Y., Nie, Z., \& Hu, C. (2015). Xylem transport and gene expression play decisive roles in cadmium accumulation in shoots of two oilseed rape cultivars (Brassica napus ). Chemosphere . https://doi.org/10.1016/j.chemosphere.2014.09.099

Yamaguchi, C., Takimoto, Y., Ohkama-Ohtsu, N., Hokura, A., Shinano, T., Nakamura, T., Suyama, A., \& Maruyama-Nakashita, A. (2016). Effects of cadmium treatment on the uptake and translocation of sulfate in Arabidopsis thaliana . Plant and Cell Physiology . https://doi.org/10.1093/pcp/pcw156

Ye, W. L., Wood, B. A., Stroud, J. L., Andralojc, P. J., Raab, A., McGrath, S. P., Feldmann, J., \& Zhao, F. J. (2010). Arsenic speciation in phloem and xylem exudates of castor bean. Plant Physiology . https://doi.org/10.1104/pp.110.163261

Yin, Y., Li, S., Liao, W., Lu, Q., Wen, X., \& Lu, C. (2010). Photosystem II photochemistry, photoinhibition, and the xanthophyll cycle in heat-stressed rice leaves. Journal of Plant Physiology . https://doi.org/10.1016/j.jplph.2009.12.021 
Zhang, P., Wang, R., Ju, Q., Li, W., Tran, L. S. P., \& Xu, J. (2019). The R2R3-MYB transcription factor MYB49 regulates cadmium accumulation.Plant Physiology . https://doi.org/10.1104/pp.18.01380

Zhou, Z. S., Yang, S. N., Li, H., Zhu, C. C., Liu, Z. P., \& Yang, Z. M. (2013). Molecular dissection of mercury-responsive transcriptome and sense/antisense genes in Medicago truncatula. Journal of Hazardous Materials . https://doi.org/10.1016/j.jhazmat.2013.02.011

Table 1. Concentration of ascorbic acid (ASA), reduced (GSH) and oxidized (GSSG) glutathione (in nmol g-1 $\mathrm{FW}$ ) measu

\section{SHOOTS}

\section{ROOTS}






Fig.1 Summary of HPLC analysis of biothiol concentrations in shoots and roots (in nmol.g ${ }^{-1} \mathrm{FW}$ ) in wild type (Col-0), cad2-1, pad2-1, rax1-1 and cad1-3 Arabidopsis thaliana treated with 0 and $3 \mu \mathrm{M} \mathrm{Hg}$ for $72 \mathrm{~h}$. Different biothiols are represented by spheres with different colours, with sphere diameters proportional to concentrations found. The concentration-to-volume scale is represented by the grey spheres at the bottom. For statistics and complete description of concentration values, please see Supplementary Table 1. 


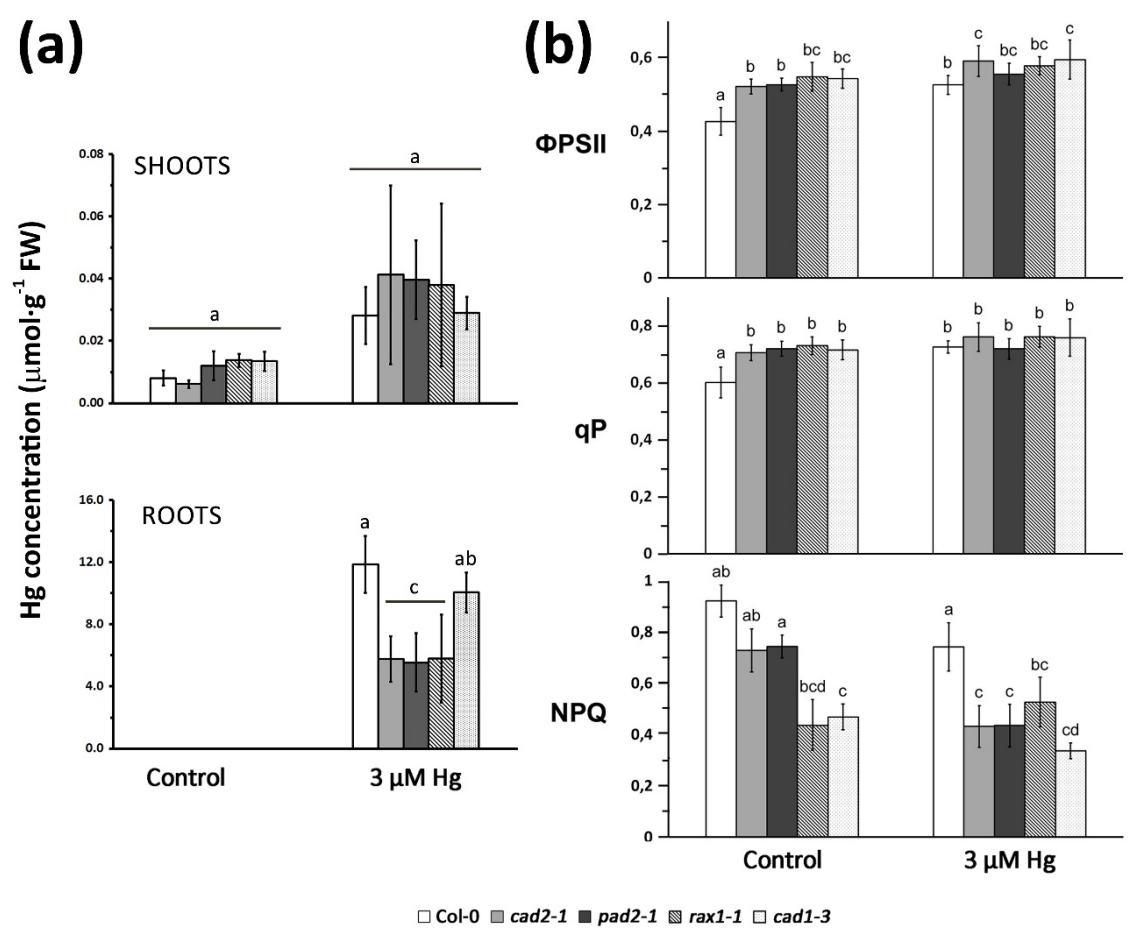

Fig. 2 (a) Mercury concentrations (in $\mu \mathrm{mol} \cdot \mathrm{g}^{-1} \mathrm{FW}$ ) in roots and shoots, and $(\mathrm{n}=4)(\mathrm{b})$ chlorophyll fluorescence parameters in wild type (Col-0),cad2-1 , pad2-1, rax1-1 and cad1-3 Arabidopsis thaliana treated with 0 and $3 \mu \mathrm{M} \mathrm{Hg}$ for $72 \mathrm{~h}$ : PSII efficiency $\left(\Phi_{\mathrm{PSII}}\right)$, photochemical quenching $\left(q_{P}\right)$ and non-photochemical quenching $(\mathrm{NPQ})(\mathrm{n}=8)$. Different letters denote significant differences at $p<0.05$ 

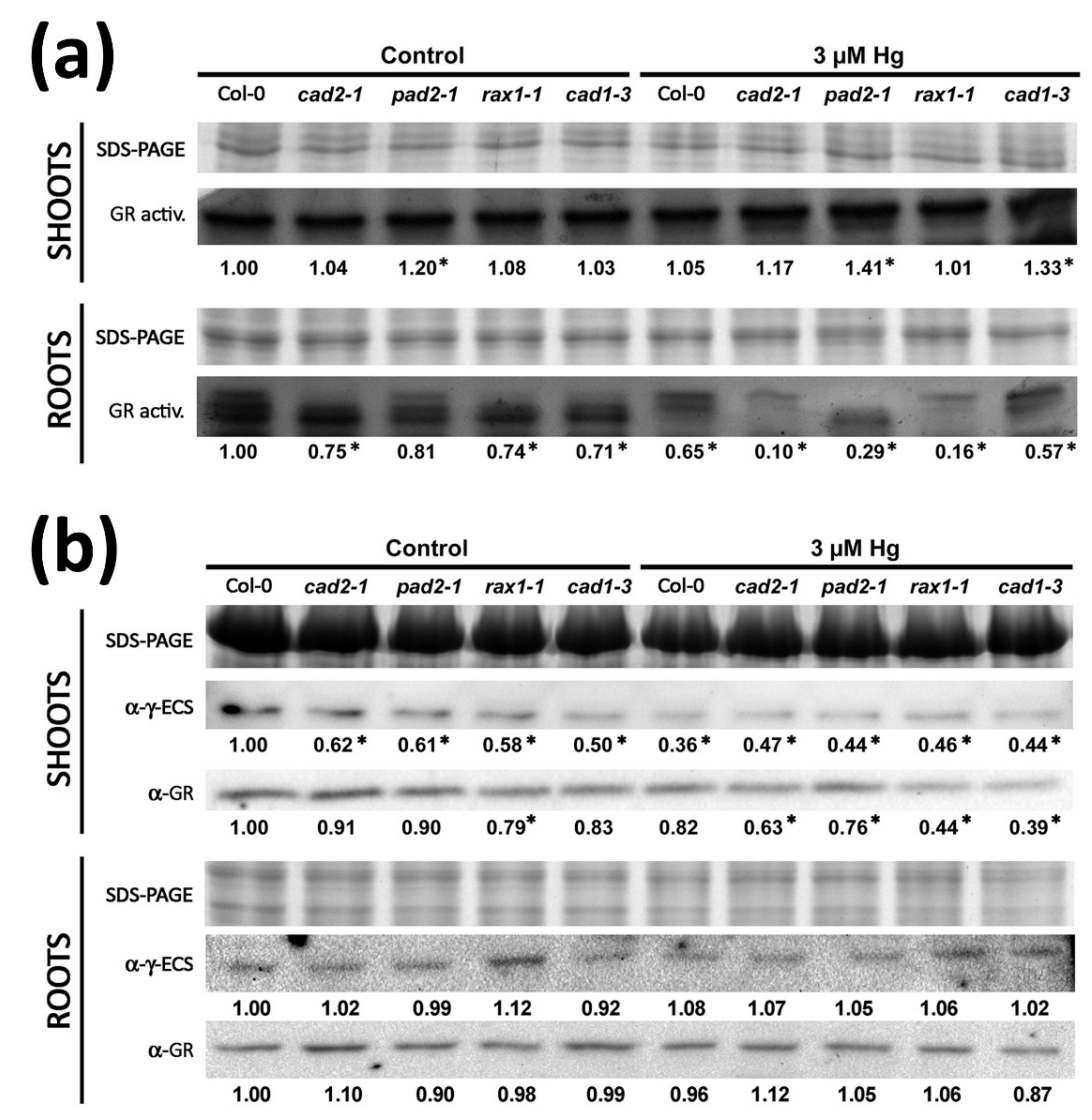

Fig. 3 (a) Glutathione reductase (GR) in gel activity, and (b) $\gamma$-glutamylcysteine synthetase ( $\gamma$ ECS) and glutathione reductase (GR) immunodetection in wild type (Col-0),cad2-1, pad2-1, rax1-1 and cad1-3 Arabidopsis thaliana treated with 0 and $3 \mu \mathrm{M} \mathrm{Hg}$ for $72 \mathrm{~h}$. Coomassie-blue staining was used to assure an equivalent protein loading of samples. Numbers represent the fold-change relative to the control Col-0, with asterisks marking decreases and decreases [?] $20 \%$. 

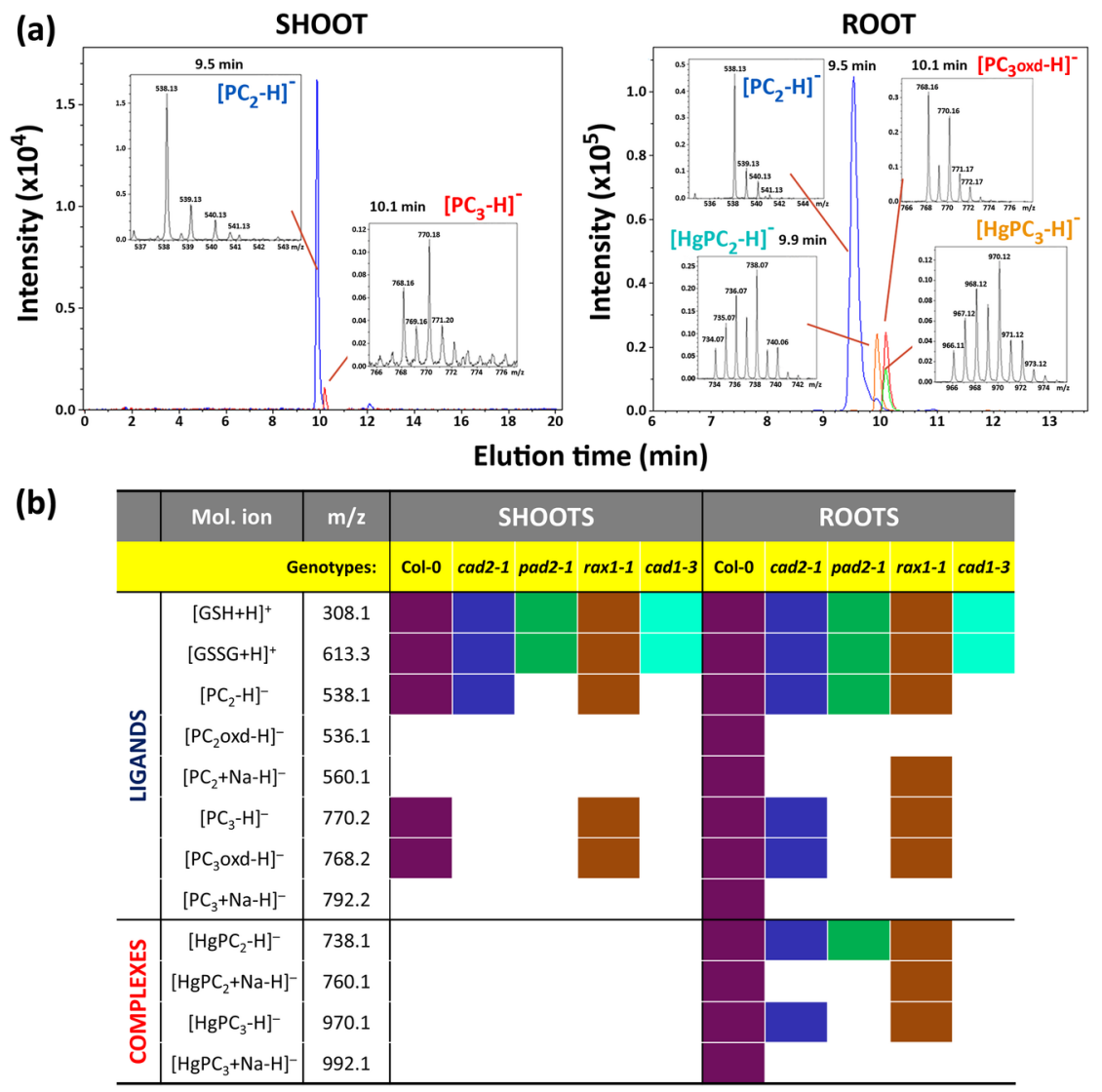

Fig. 4. PCs and Hg-PC complexes detected by HPLC-ESI-MS(TOF).(a) Examples of free PCs and Hg-PCs found in shoots and roots of Col-0 plants exposed to $3 \mu \mathrm{M} \mathrm{Hg}$ for $72 \mathrm{~h}$. Chromatographs and characteristic MS spectra of several molecular ions are shown (in negative mode). (b) Summary table describing the different molecular ions of biothiol ligands and Hg-PC complexes detected in shoots and roots of all Arabidopsis genotypes treated with $3 \mu \mathrm{M} \mathrm{Hg}$ for $72 \mathrm{~h}$. HPLC-ESI-MS(TOF) was carried out in negative and positive modes, and major detected molecular ions $(\mathrm{m} / z)$ are shown. 

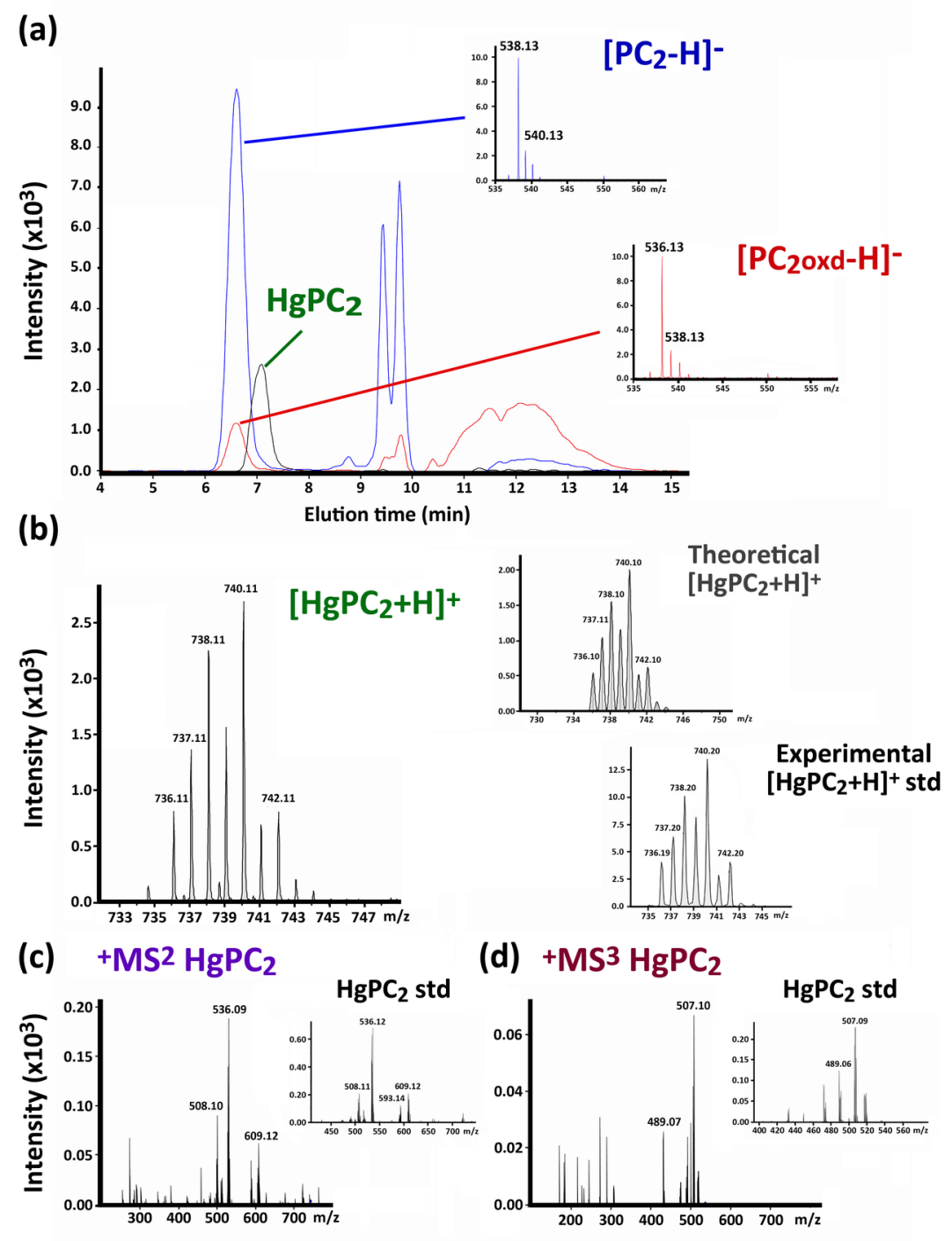

(d) $+\mathrm{MS}^{3} \mathrm{HgPC}_{2}$



Fig. 5 HPLC-ESI-MS(TOF) analysis of PC and Hg-biothiol complexes in Arabidopsis Col-0 xylem sap. (a)Chromatographic profile of reduced $\mathrm{PC}_{2}$, oxidized $\left(\mathrm{PC}_{2}\right.$ oxd), and $\mathrm{HgPC}_{2}$ detected in the xylem samples (in negative mode). (b) $\left[\mathrm{HgPC}_{2}+\mathrm{H}\right]^{+}$Molecular ion distribution (in $\mathrm{m} / z$ ) compared with the theoretical one and a standard complex, prepared by mixing $\mathrm{PC}_{2}: \mathrm{HgCl}_{2}$ at $10: 10 \mu \mathrm{M}$ ratio (in positive mode). (c) and (d) $\mathrm{MS}^{2}$ and $\mathrm{MS}^{3}$ fragmentation profiles of $\left[\mathrm{HgPC}_{2}+\mathrm{H}\right]^{+}$, compared to those obtained using a standard $\mathrm{PC}_{2}: \mathrm{HgCl}_{2}$ mixture (insets), all in positive mode. 


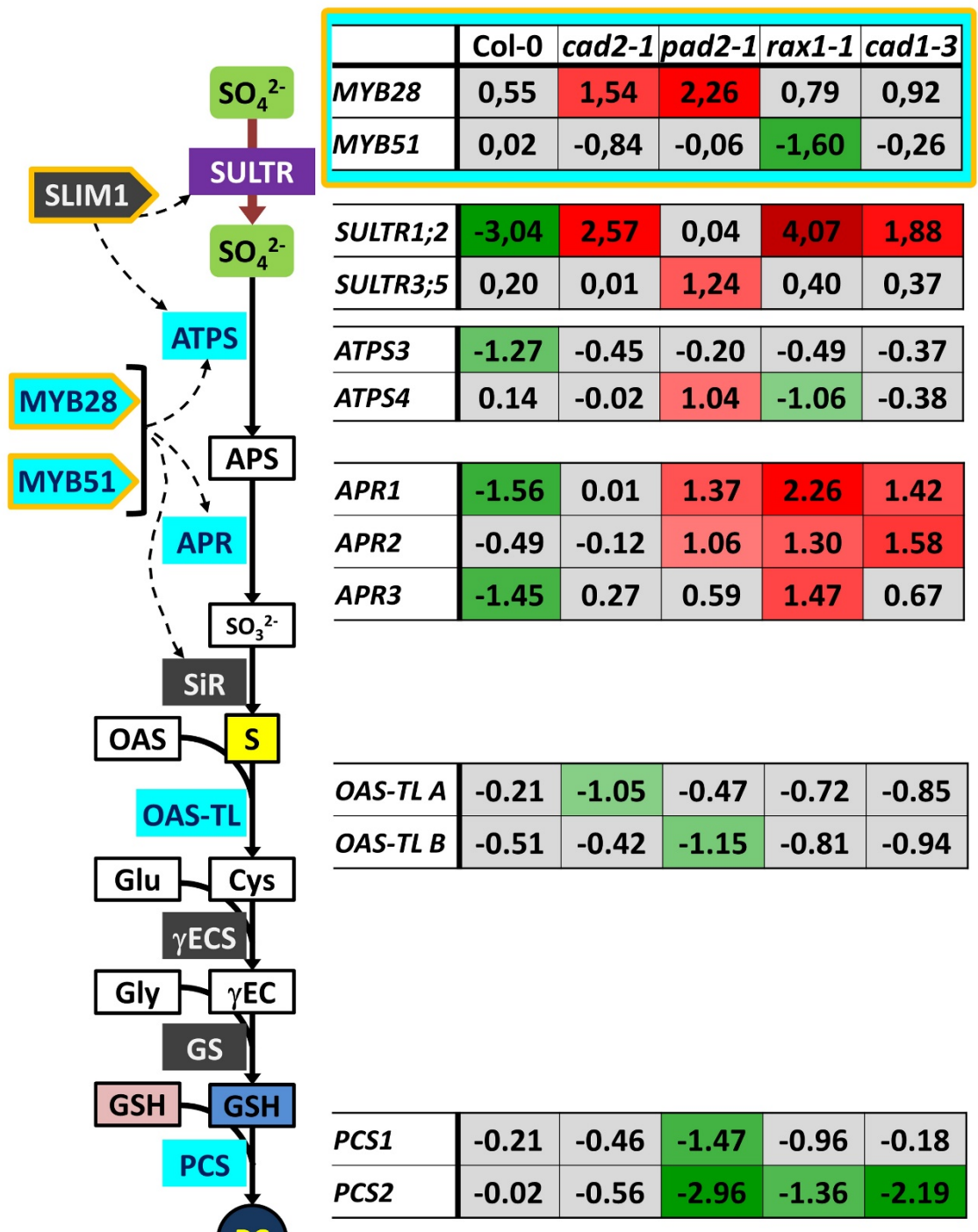

PC

Fig. 6. Shoot transcriptional qRT-PCR profile of selected genes related to sulphur metabolism, using Col-0, cad2-1,pad2-1, rax1-1 and cad1-3 Arabidopsis treated with 0 or $3 \mu \mathrm{M} \mathrm{Hg}$ for 72 h. Values are presented as $\log _{2}$-fold change of $\mathrm{Hg}$-treated plants relative to control plants of each genotype. Statistical differences with Col-0 (at $p<0.05$ ) are represented as red and green boxes for over- and down-regulated genes, respectively. Grey boxes indicate no statistical differences. Data of genes encoding transcription factors () are shown in the inset box (). Light blue boxes also highlight genes differentially expressed. See quantitative values and statistics in Supplementary Table 3. 


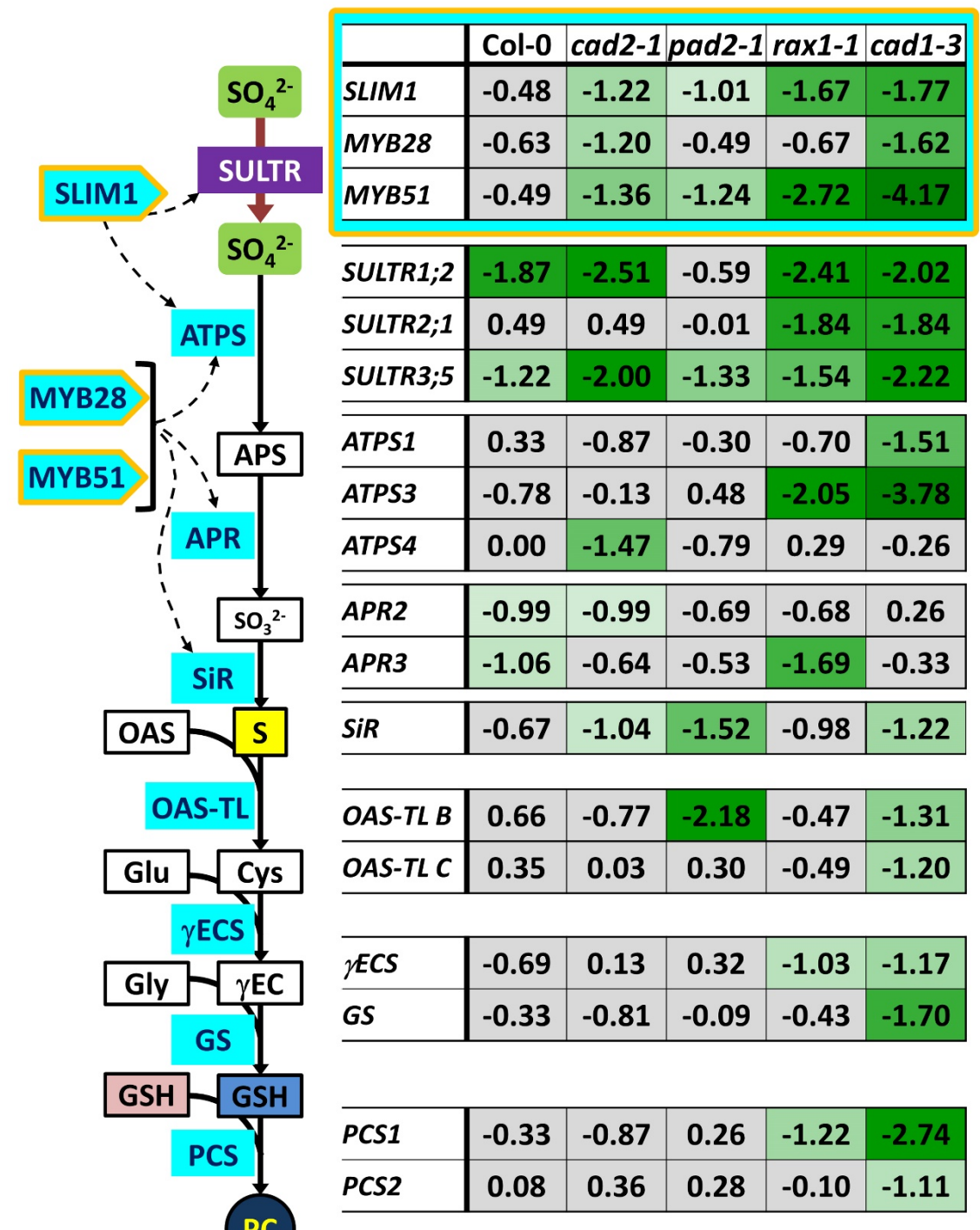

PC

Fig. 7. Root transcriptional qRT-PCR profile of selected genes related to sulphur metabolism in Col-0, cad2-1 , pad2-1 ,rax1-1 and cad1-3 Arabidopsis treated with 0 or $3 \mu \mathrm{M} \mathrm{Hg}$ for $72 \mathrm{~h}$. Values are presented as $\log _{2}$-fold change of $\mathrm{Hg}$-treated plants relative to control plants of each genotype. Statistically down-regulated genes when compared to Col-0 (at p < 0.05) are represented as green boxes, whereas grey boxes indicate no statistical difference. Data of genes encoding transcription factors () are shown in the inset box (). Light blue boxes highlight genes differentially expressed. See quantitative values and statistics in Supplementary Table 4 . 